\title{
Chapter 3 \\ Structural Molecular Insights into SARS \\ Coronavirus Cellular Attachment, Entry and Morphogenesis
}

\author{
Daniel R. Beniac and Timothy F. Booth
}

\begin{abstract}
Coronavirus spikes have the largest mass of any known viral spike molecule. The spike is a type 1 viral fusion protein, a class of trimeric surface glycoprotein proteins from diverse viral families that share many common structural and functional characteristics. Fusion proteins are mainly responsible for host cell receptor recognition and subsequent membrane fusion, and may perform other roles such as virus assembly and release via budding. The conformational changes that occur in the spike of intact SARS coronavirus (SARS-CoV) when it binds to the viral receptor, angiotensin-converting enzyme 2 (ACE2) are described. Clues to the structural/functional relationships of membrane fusion have been made possible by the development of viral purification and inactivation methods, along with cryoelectron microscopy (cryo-EM) and three-dimensional (3D) image processing of many different images containing multiple views of the spikes. These methods have allowed study of the spikes while still attached to virions that are noninfectious, but fusionally competent. The receptor-binding and fusion core domains within the SARS-CoV spike have been precisely localized within the spike. Receptor binding results in structural changes that have been observed in the spike molecule, and these appear to be the initial step in viral membrane fusion. A working model for the stepwise process of receptor binding, and subsequent membrane fusion in SARS-CoV is presented. Uniquely, the large size of the SARS-CoV spike allows structural changes to be observed by cryo-EM in the native state. This provides a useful model for studying the basic process of membrane fusion in general, which forms an essential part of the function of many cellular processes.
\end{abstract}

\footnotetext{
T.F. Booth $(\square)$

Viral Diseases Division, National Microbiology Laboratory, Public Health Agency of Canada, 1015 Arlington Street, Winnipeg, Manitoba R3E 3R2, Canada

e-mail: Tim_Booth@phac-aspc.gc.ca
} 


\subsection{Structure of SARS Coronavirus (SARS-CoV)}

The earliest coronavirus isolates were identified from mammalian and avian sources in the 1930s and 1940s (Beaudette and Hudson 1937; Doyle and Hutchings 1946; Cheevers and Daniels 1949). At this time, electron microscopy revealed prominent large spikes on the surface of virions, whose resulting crown-like appearance gave rise to the name coronavirus (Fig. 3.1). Coronaviruses have 4-5 structural proteins including the spike protein $(\mathrm{S})$, envelope protein $(\mathrm{E})$, membrane protein $(\mathrm{M})$, nucleocapsid protein $(\mathrm{N})$, and members of the coronavirus phylogenetic subgroup 2a have a shorter $\mathrm{S}$ protein called hemagglutinin esterase (HE). The SARS-CoV genome is unusually large at $\sim 29.7 \mathrm{~kb}$, and encodes 14 open reading frames for several proteins, (Marra et al. 2003; Rota et al. 2003). On the interior, the lipid envelope of SARS-CoV appears to have a gap observed as a low density in three-dimensional (3D) structures (Fig. 3.2) and then a more dense layer, which is presumably the surface of the nucleocapsid comprising mainly the $\mathrm{N}$ protein. Details of how this nucleocapsid is organized are not clear; however, the $\mathrm{N}$ protein is presumably anchored to the cytoplasmic side of the virion envelope via the

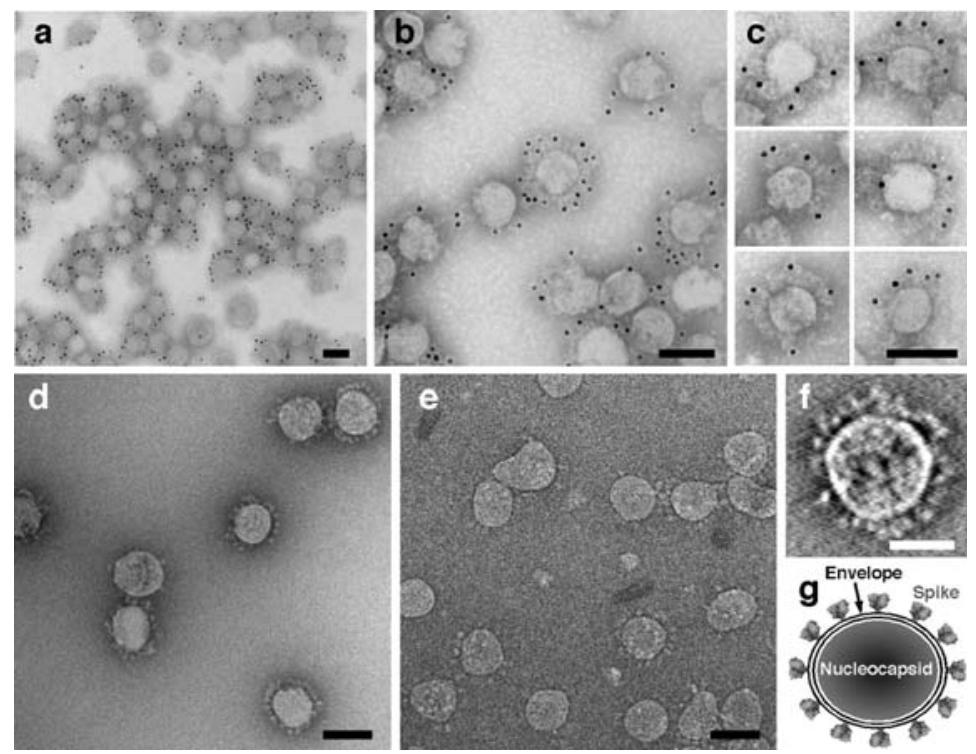

Fig. 3.1 EM images of $\gamma$-irradiated SARS-CoV. Immuno-EM with $10 \mathrm{~nm}$ gold confirmed the attachment of neutralizing antibodies to the spike $(\mathbf{a}, \mathbf{b})$, and the binding of soluble ACE2 to the spike (c). (d) SARS-CoV negative-stained with methylamine tungstate shows the virions to be spherical/pleomorphic, with the spikes clearly visible from the side perspective. (e) Cryo-EM provides additional details including the end-on perspective views of the spikes. (f) The central section of an electron tomogram of a negative-stained SARS-CoV clearly shows the viral envelope with the spikes attached. (g) Schematic model of SARS-CoV. Scale bars: (black) 1,000 $500 \AA$ 

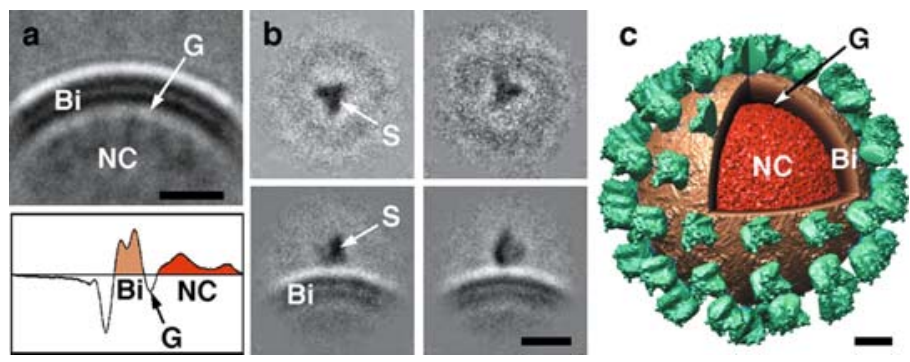

Fig. 3.2 Image analysis was employed to investigate the spike of SARS-CoV. (a) Image average of the virion clearly shows the lipid bilayer (Bi), a prominent gap (G), and the nucleocapsid (NC). (b) 2D class averages of the spike (S) presenting end-on and side-view perspectives. (c) 3D model of SARS-CoV, with a wedge cut out of it to reveal the nucleocapsid. Legend: (S) spike, green; (Bi) lipid bilayer, beige; (G) gap; (NC) nucleocapsid, red. Scale bar: $150 \AA$

$\mathrm{M}$ protein, which is a low abundance protein and may account for the "gap" of low density between the envelope and the nucleocapsid. Electron microscopic examination shows no evidence for supercoiled RNA such as that seen in paramyxoviruses and the interior appears amorphous by cryo-electron microscopy (cryo-EM); hence the arrangement whereby the RNA may be bound to the nucleocapsid protein is not clear.

A striking feature of the SARS-CoV spike is its huge mass ( $\sim 500 \mathrm{kD}$ per trimer). However, despite the size differences, the SARS-CoV spike performs the same fundamental task in viral entry to the host cell as other smaller type 1 viral fusion proteins, such as the influenza hemagglutinin (HA) ( 220 kD per trimer). The SARS-CoV spike can be subdivided into four structural domains (from $\mathrm{N}$ to $\mathrm{C}$ terminus); two large external domains $\mathrm{S} 1$ and $\mathrm{S} 2$ are largely responsible for receptor binding and membrane fusion, respectively. In most type 1 viral fusion proteins the analogous peptides are generated by proteolysis of the spike precursor during the maturation process in the host cell, yielding two peptides with the fusion peptide on the $\mathrm{N}$ terminus of $\mathrm{S} 2$. In SARS-CoV the S1/S2 assignment is given based on sequence homology to other viral fusion proteins, although there appears to be no peptide cleavage. The final two small domains are comprised of a transmembrane domain, and a carboxyterminal cytoplasmic domain. The cell-surface molecule angiotensin-converting enzyme 2 (ACE2) is the receptor for the SARS-CoV S protein ( $\mathrm{Li}$ et al. 2003) which is a relatively large macromolecule with a diameter of $70 \AA$. By comparison, the receptor for influenza HA, sialic acid, is much smaller with a $10 \AA$ diameter.

One of the challenges of achieving structural molecular studies with native SARS-CoV is that it is classified as a biological safety level 3 organism, requiring handling in containment. However, once it was shown that specimens could be $\gamma$-irradiated with a sufficient dose $(2 \mathrm{Mrad})$ for viral inactivation, while still preserving protein structure, it was possible to carry out cryo-EM of intact virions and to obtain the 3D structure of the native, unfixed virions and the spike, using single particle image processing and averaging from multiple images containing 
many different viewing angles of the molecule (Booth et al. 2005; Beniac et al. 2006). Immunolabeling showed that these virions were intact antigenically as well as structurally (Fig. 3.1) and still able to bind to the SARS-CoV receptor, ACE2.

\subsection{Structure of the Coronavirus Spike}

Cryo-EM coupled with 3D single-particle image analysis has been used to determine the structure of the SARS-CoV spike, and positioning of the binding of ACE2 to the spike (Beniac et al. 2006, 2007). Spikes on the surface of virus particles are readily imaged by cryo-EM in the frozen-hydrated native state (Fig. 3.1e). 3D image processing was carried out on selected spikes using single-particle image processing (Penczek et al. 1994; Frank et al. 1996; Beniac et al. 2006). The structures of both the spike and the spike-ACE2 complex have been solved to $18.5 \AA$ resolution (Figs. 3.2 and 3.3; Beniac et al. 2006, 2007). The spike shows a striking structure, being about $180 \AA$ in diameter and with three distinct lobes or domains $50 \AA$ thick on each subunit of the trimer (similar in appearance to the blades of a propeller), and a thin stalk connecting the spike to the viral envelope. The blades are twisted at an angle of $\sim 30^{\circ}$ to the axis of symmetry, and are almost certainly composed of the spike $\mathrm{S} 1$ domain.

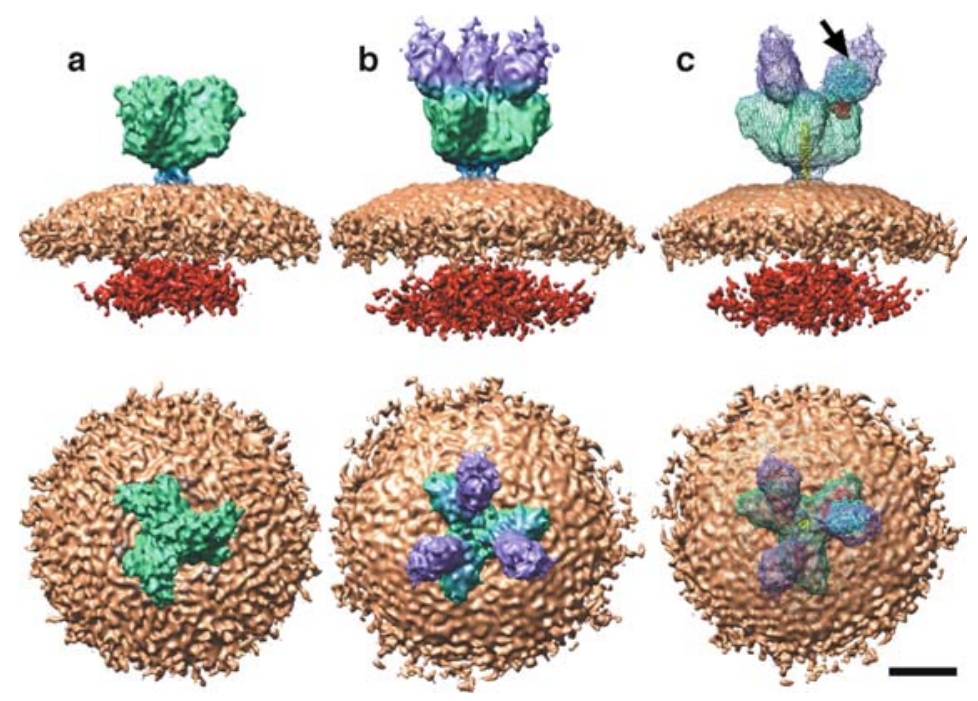

Fig. 3.3 3D reconstructions presented as shaded surfaces are shown from the side (upper) and end-on (lower) perspectives. Cryo-EM reconstruction of the SARS-CoV spike (a), and SARSCoV spike-ACE2 complex (b). (c) The atomic resolution structures were docked within the SARS-CoV spike-ACE2 3D reconstruction; PDB ID code: 2AJF (ACE2, blue; receptor-binding domain, red), and 2FXP (yellow). The arrow points to the C terminus of ACE2. Color scheme: ACE2, violet; spike, green; stalk, blue; envelope, beige; nucleocapsid, red. Scale bar: $100 \AA$ 

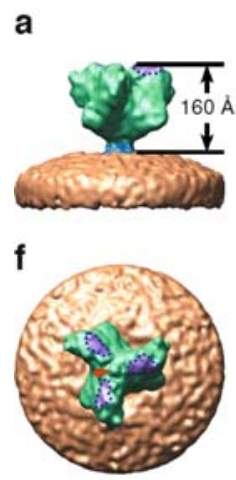

b

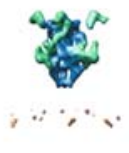

g

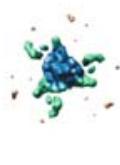

c

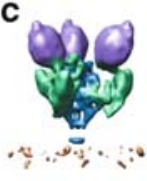

h

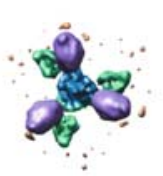

d

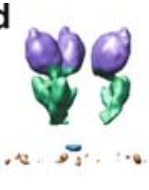

i

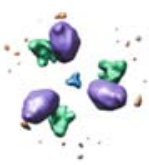

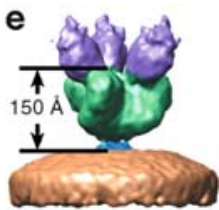

j

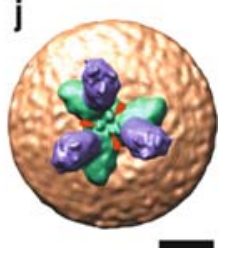

Fig. 3.4 The cryo-EM reconstruction of the SARS-CoV spike (a,f) was subtracted from the SARS-CoV spike-ACE2 complex $(\mathbf{e}, \mathbf{j})$. The positive component attributed to the SARS-CoV spike in $(\mathbf{b}, \mathbf{g})$ indicates a rearrangement in the $\mathrm{S} 2$ core, and the positive component attributed the SARS-CoV-ACE2 complex shows the addition of ACE2 and an exterior rearrangement in S1 (d,i). The net difference map is presented in $(\mathbf{c}, \mathbf{h})$. The structures are presented from a side perspective (a-e) and end-on perspective $(\mathbf{f}-\mathbf{j})$. The arrows in (f) and (j) illustrate the mass reorganization that occurs in the central axis of the spike where one small central blob splits into three nubs. In (a,f) the region on the spike adjacent to ACE2 which corresponds to the receptor-binding domain has been highlighted with a dotted line and is colored purple. The color scheme is the same as in Fig. 3.3. Scale bar: $100 \AA$

ACE2 binding does not result in a fundamental structural unfolding of the spike. However, the overall height of the spike was reduced from $160 \AA$ to $150 \AA$ following binding. When viewed end-on, the spike undergoes a rotation of $\sim 5^{\circ}$ following binding, and the mass at the center of the axis of symmetry on the distal end of the spike redistributes itself. These redistributions of mass were further identified in difference maps between the two reconstructions (Fig. 3.4). Upon ACE2 binding the spike undergoes a decondensation of mass around the central axis (Fig. 3.4b,g; blue). This region is the putative location of the $\mathrm{S} 2$ domain. The difference map for the bound spike (Fig. 3.4d,i) shows changes in both the ACE2 component (purple) and the outer edges of the three "blades" of the S1 domain (green).

The precise location of ACE2 binding on the distal end of the spike is centered at $70 \AA$ from the central axis of the spike, with a $30 \AA$ gap between the axis of symmetry and ACE2. One ACE2 molecule can bind to each of the three propellerlike blades of the spike, making a structure $220 \AA$ high (Fig. 3.3b). Binding of more than one ACE2 to each spike (on one or both of the other two propeller blades of each trimer) is possible, hence binding of one ACE2 molecule does not stearically hinder binding of additional ACE2 molecules.

The cryo-EM 3D structures of the spike and the spike-ACE2 complex, when combined with the atomic resolution structures of the SARS-CoV spike receptorbinding domain - ACE2 complex (Li et al. 2005a) and the heptad repeat pre- and postfusion cores (Supekar et al. 2004; Hakansson-McReynolds et al. 2006), show that the receptor-binding domain docks to the distal end of the spike with ACE2 
filling the extra mass on the spike (shown by the color violet in Fig. 3.3). The empty upper region of the mass appears to be components of the second ACE2 and the Fc component of the chimeric protein, and the location of the $\mathrm{C}$-terminus of the docked ACE2 was consistent with this interpretation.

\subsection{Viral Membrane Fusion in SARS-CoV}

Viral membrane fusion proteins are responsible both for binding to cellular receptors, and the subsequent fusion of viral and cellular membranes. The paradigm for type 1 fusion proteins consists of two heptad repeat regions, and a hydrophobic fusion peptide (Dutch et al. 2000). This motif is present in SARS-CoV (HakanssonMcReynolds et al. 2006) and other coronaviruses (Xu et al. 2004), as well as the hemagglutinin (HA) of influenza (Skehel and Wiley 2000), gp21 of human T-cell leukemia virus type 1 (Kobe et al. 1999), gp41 of HIV(Weissenhorn et al. 1997), GP2 of Ebola (Weissenhorn et al. 1998; Malashkevich et al. 1999), and the fusion protein of paramyxovirus (Zhao et al. 2000; Chen et al. 2001). Type 1 viral fusion proteins can also be divided into two subtypes: those whose fusion mechanism is low $\mathrm{pH}$-dependent such as influenza $\mathrm{HA}$, and those that are $\mathrm{pH}$-independent like the retroviral fusion proteins. In retroviruses, receptor binding itself can trigger fusion, with temperature and redox conditions also influencing the fusion mechanism (Hernandez et al. 1997; Damico et al. 1998). The SARS-CoV spike appears to be insensitive to redox conditions (Fenouillet et al. 2007). Although the factors which trigger fusion (endocytosis, $\mathrm{pH}$ sensitivity, single receptor vs. primary and coreceptor binding, redox change) differ amongst diverse virus families, all viral fusion proteins are thought to share the same basic fusion mechanism (Baker et al. 1999; Skehel and Wiley 2000; Dutch et al. 2000; Colman and Lawrence 2003; Dimitrov 2004; Hofmann and Pohlmann 2004).

The precise mechanisms by which type 1 viral fusion proteins gain access to the host cell remain unknown. The hypothetical entry process includes several steps that take place in sequence: receptor binding, fusion core rearrangement, fusion peptide insertion in host cell membrane, refolding of heptad repeats, membrane fusion, and finally viral nucleocapsid transfer (Earp et al. 2005).

\subsection{Cellular Attachment and Entry of SARS-CoV}

In most proposed models of membrane fusion it is postulated that the $\mathrm{S} 1$ domain or analogous receptor-binding domains dissociate from the spike during the membrane fusion process. This dynamic process was demonstrated for influenza HA by Kemble et al. (1992) in their investigation where they engineered intermonomer disulfide bonds between the HA S1 subunits. The result of this was that fusion activity was impaired; however it could be restored under reducing conditions. It is 
probable that the SARS-CoV spike shares a similar mechanism, with the structural changes detected by cryo-EM representing the initial step in this process.

By analogy with other type 1 viral fusion proteins, the fusion core of the SARS$\mathrm{CoV}$ spike is thought to undergo similar structural rearrangements during fusion. The receptor-binding domain is localized in a position on the distal end of the molecule, closer to the 3 -fold axis than anticipated, yet still in a position that would not impede these structural rearrangements. Putative mechanisms by which type 1 viral fusion proteins achieve membrane fusion have been proposed (Baker et al. 1999; Skehel and Wiley 2000; Dutch et al. 2000; Colman and Lawrence 2003; Dimitrov 2004), but complete structural evidence for the role of intermediate structures in these mechanisms has yet to be obtained. The structural biology of this process has been best characterized for the influenza HA, and paramyxovirus fusion protein $(\mathrm{F})$ for which the prefusion and membrane fusion $\mathrm{pH}$ structures have been determined by X-ray crystallography (Sauter et al. 1992; Bullough et al. 1994; Skehel and Wiley 2000; Yin et al. 2005, 2006) (Fig. 3.5, inset). All of the subsequent models for type 1 viral fusion proteins are based on the structural data of these two fusion proteins. A drawback in all of these models is that they are based on recombinant ectodomains that are not proven to exist as a component in the complete molecule, and they lack both membrane-interacting residues and lipids (Skehel and Wiley 2000). The cryo-EM structures of intact SARS-CoV spike bound to native virion lipid envelopes are very instructive when atomic resolution fragments are docked within the overall molecule, especially as the entire SARS-CoV spike has proven to be a difficult subject for X-ray crystallography, and atomic resolution data exist for only a few fragments of the SARS-CoV spike. This structural data has been modeled into a scheme to propose a mechanism for SARS-CoV spike-mediated membrane fusion (Figs. 3.5 and 3.6). In the initial step the receptor-binding domain of the spike attaches to its human receptor ACE2. At this point the fusion core is in the prefusion configuration with the three heptad 2 repeats (HR2) forming a coiled-coil symmetric trimer at the center of the stalk of the spike (Hakansson-McReynolds et al. 2006).

During the next step of the membrane fusion process the virus is internalized in the cell by endocytosis and is exposed to a low $\mathrm{pH}$ environment, and may undergo proteolytic cleavage between the S1 and S2 domains (Simmons et al. 2005). The next step is fusion core rearrangement, so that the fusion peptide (FP) inserts into the host cell membrane. In Fig. 3.5 this initial process is illustrated with models M0-M3, based on the atomic structure of the HR2 prefusion core, which begins to collapse upon itself in model M3 in a manner similar to that which occurs with influenza HA (Skehel and Wiley 2000). The inset in Fig. 3.5 illustrates this process in HA by coloring segments of S2 to illustrate the rearrangement from M0 to M3 that takes place. During this process we propose that the receptor-binding domain still holds on to ACE2 so that the fully extended fusion peptide will be positioned to penetrate through the host membrane. Our cryo-EM results show that it is possible for the spike to attach to three ACE2 receptors at once; this may serve to hold on to the host membrane like a tripod so as to accurately orientate the fusion core (Fig. 3.7). In addition the $30 \AA$ gap between the axis of symmetry and ACE2 


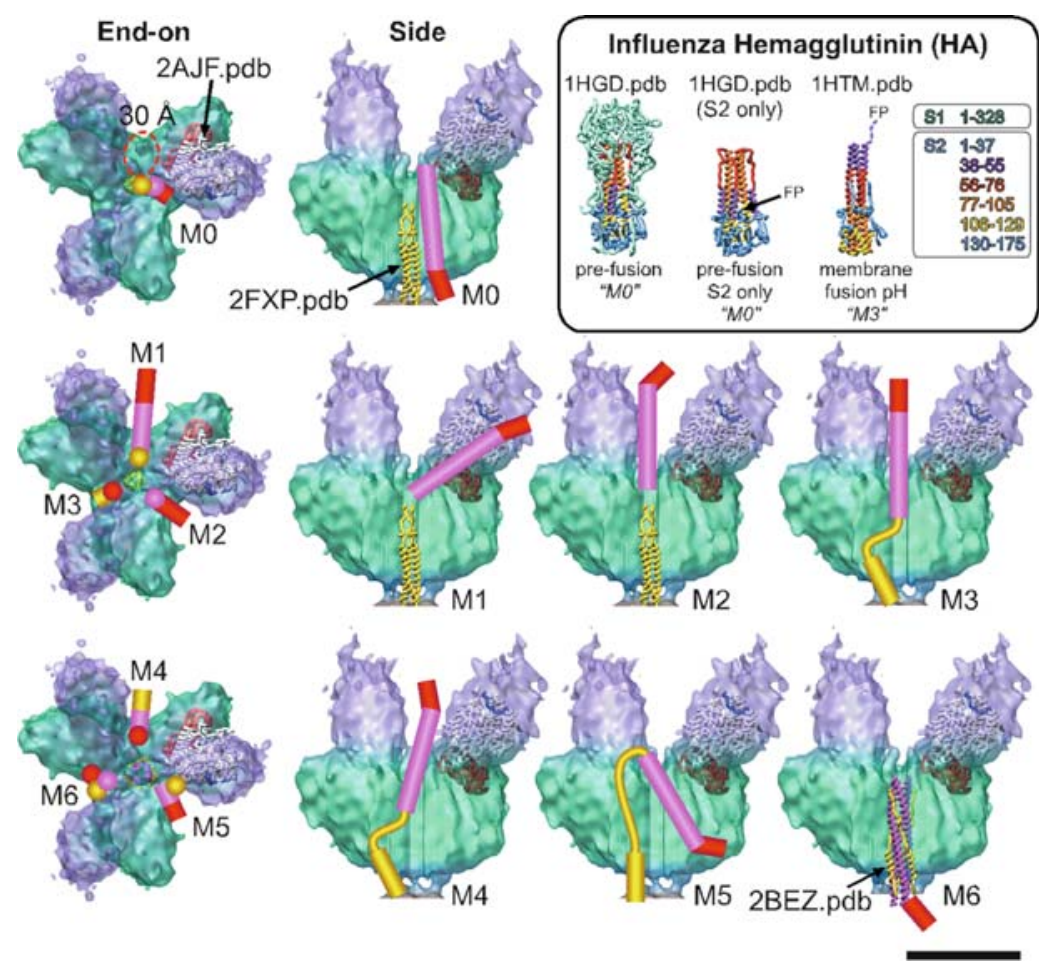

Fig. 3.5 Seven models (M0-M6) are presented which show the hypothetical rearrangement of the SARS-CoV fusion core which takes place during membrane fusion. For simplicity we show only one of the three HR1/HR2 structures for each cylindrical model. Models were constructed based on the structures for influenza HA, presented in the inset at the same scale. The cryo-EM, docked ACE2-receptor-binding domain, and prefusion core (M0) and postfusion core (M6) structures provided start and end points for modeling spike rearrangement. Five intermediate models illustrate the "jack-knife" mechanism of the fusion core. The following color scheme was used: cryo-EM surface: same as in Fig. 3.3. Ribbon structures: ACE2, white (C terminus blue; spike receptor-binding domain, red; HR1, pink; HR2, yellow. Cylindrical models: FP, red; HR1, pink; HR2, yellow. Scale bar: $100 \AA$

provides sufficient space for fusion core rearrangement. Damico et al. (1998) demonstrated that the kinetics of binding of the Rous sarcoma virus envelope protein ectodomain to liposomes was not linear with respect to receptor concentration. This suggested that activation of the trimeric ectodomain favored binding to multiple receptor monomers. One can therefore infer that other structurally homologous viral envelope proteins can also bind multiple receptors, which may be a general adaptation that provides the correct temporal and spatial arrangement to bring about membrane fusion. The observation that the SARS-CoV spike could bind three soluble ACE2 receptors provides three possible binding states with one, two or three membrane-bound receptors attached to the spike. In Fig. 3.7 we present these three states; with only one receptor bound the spike and virus have a wide range of movement possible, whereas with two receptors bound the movement is 


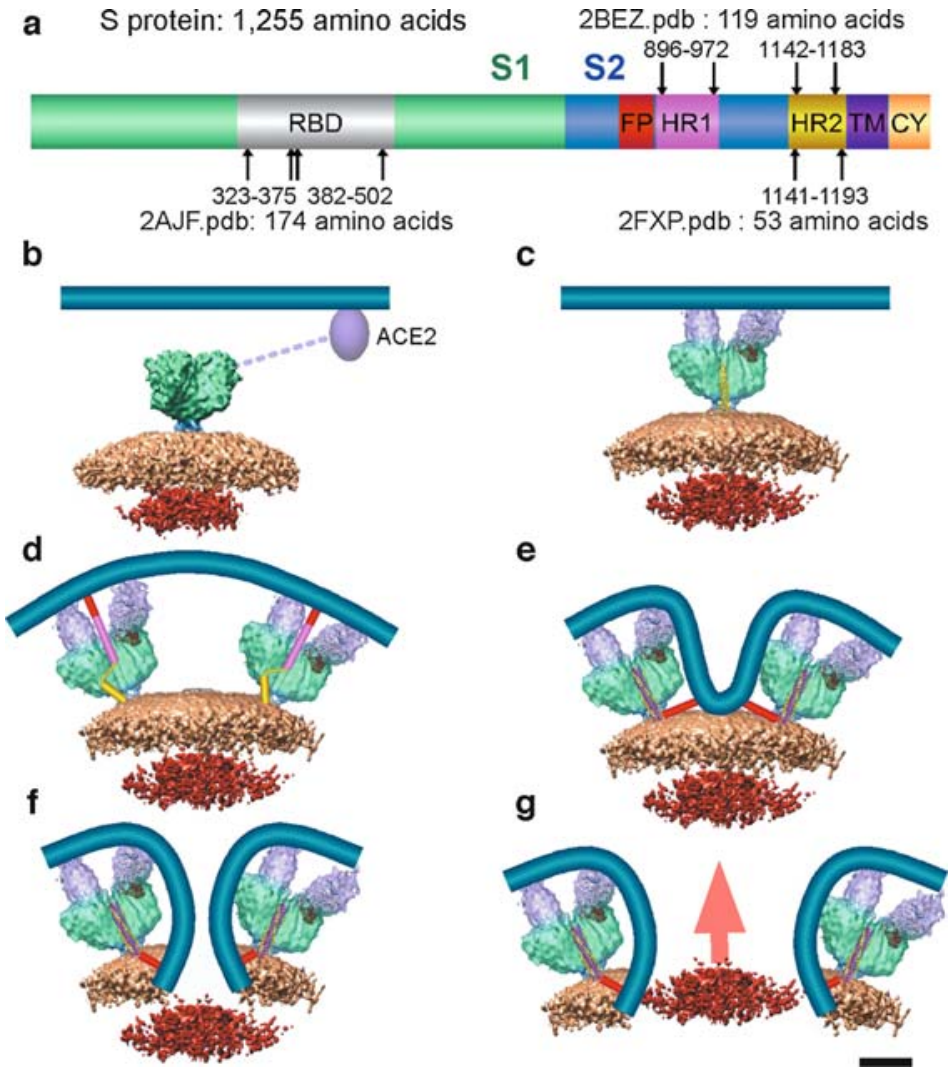

Fig. 3.6 A schematic of the SARS-CoV spike protein with the location of the known atomic structures is presented in (a). The following abbreviations are used: RBD, receptor-binding domain; FP: fusion peptide; HR1: heptad repeat 1; HR2: heptad repeat 2; TM: transmembrane; CY: cytoplasmic tail. There are several steps involved in viral entry; they can be broken down into at least six components: (b) receptor targeting, (c) viral attachment, (d) fusion core rearrangement and fusion peptide insertion, (e) fusion core refolding, (f) membrane fusion, and (g) nucleocapsid transfer. In (b-g) the host membrane is represented using a shaded blue line. The color scheme used is the same as in Figs. 3.3 and 3.5. Scale bar: $100 \AA$

greatly restricted to motion in one plane only. Only in the case of three bound receptors will the spike and its fusion core be arranged perpendicular to the cell surface with minimal movement possible. At present it has not been demonstrated that membrane fusion requires the fusion core to be oriented perpendicular to the host cell membrane to function. However, one can hypothesize this based on the orientation of ACE2 on the distal end of the SARS-CoV spike. It is interesting to note that binding to three receptor molecules is the minimum number of binding events required to achieve this perpendicular orientation in 3D space. This observation matches up with the conserved trimeric structures of type 1 fusion proteins which are common amongst enveloped viruses, thus indicating that a possible conserved structural-functional relationship may exist. 


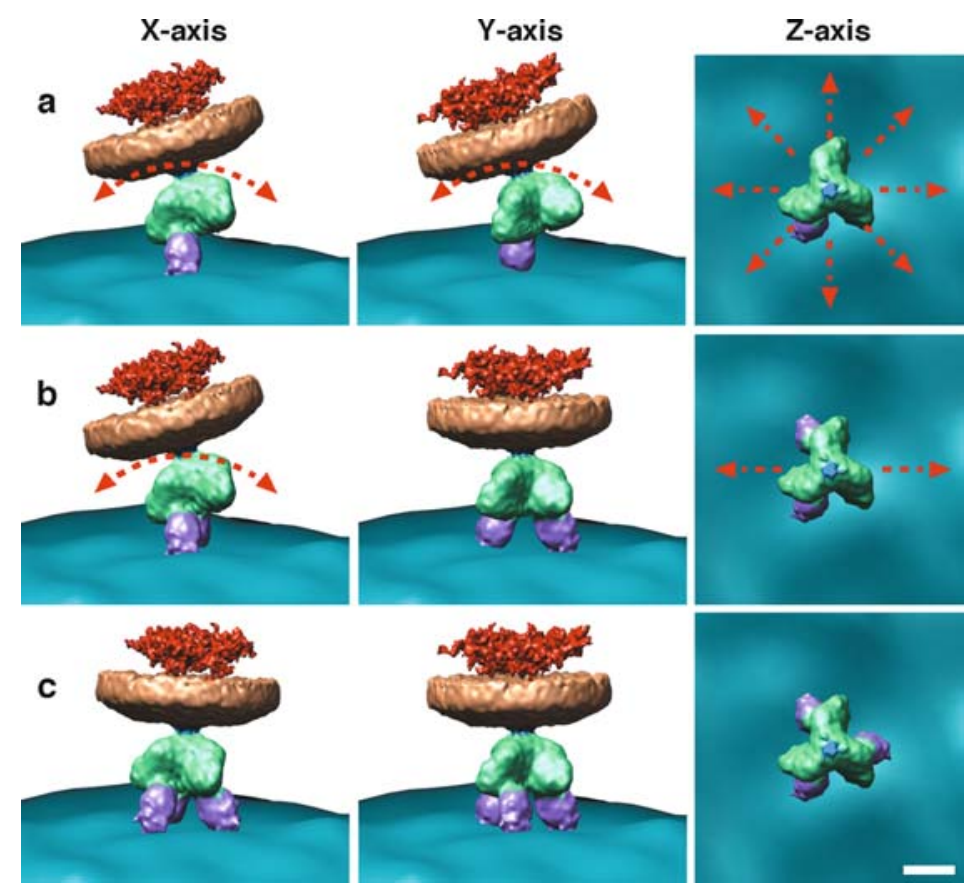

Fig. 3.7 The binding of the SARS-CoV spike to multiple receptors is presented from three $90^{\circ}$ orthographic views ( $X, Y$, and $Z$ axes). When one receptor is bound there is a wide range of motion possible (a). By binding two receptors the freedom of movement is greatly reduced to motion in one plane (b). When three receptors are bound, the spike is positioned in such a way that movement is restrained and the fusion core is perpendicular to the host cell membrane (c). The host membrane is represented using a shaded blue surface (same as in Fig. 3.6), and the color scheme used for the SARS-CoV spike is the same as in Fig. 3.3. Scale bar: $100 \AA$

The next step in the membrane fusion process involves the refolding of the fusion core back upon itself to adopt the postfusion configuration (Supekar et al. 2004) (Fig. 3.5; models M4-M6). In this configuration three heptad 1 repeats (HR1) form a parallel coiled-coil trimer, and the three HR2 pack in an antiparallel fashion in the hydrophobic grooves of the HR1 trimer. The result of this is that both the FP and transmembrane regions of the spike are brought in close proximity to each other, resulting in the host and viral membranes being in close contact. Each SARS$\mathrm{CoV}$ virion has an average of 65 spikes (Beniac et al. 2006). At this density, several spikes would be close enough together to act in concert to disrupt the plasma membrane and induce pore formation between viral and cellular membranes. Opening of these pores would allow the SARS-CoV nucleocapsid to enter the host cell cytoplasm, as shown in our model in Fig. 3.6. Multiple SARS-CoV spike trimers may be involved in formation of the fusion pore, similar to the situation in influenza, where it has been suggested that between three and six HA trimers may be involved in the production of each fusion pore (Skehel and Wiley 2000). In Figs. 3.5 and 3.6 we have presented the ACE2-SARS:S1 domains as they 
were solved in this cryo-EM investigation, for the model of membrane fusion that we present. For other fusion proteins like influenza HA1 and HIV GP120 it has been modeled that the rearrangements upon membrane fusion are dramatic involving a shedding of the above-mentioned domains. The cryo-EM investigations have detected structural movement of S1 upon ACE2 binding, which could represent the initial phase of this dramatic process that is postulated to occur in the course of membrane fusion.

An analysis of the structure of the spike-receptor complex demonstrates how SARS-CoV can adapt to utilize receptors from different species and how they may evolve to gain specificity for new receptor types, in that there is redundancy and a great deal of protein mass that can accommodate evolutionary changes. RNA viruses have a high rate of mutation and recombination (Moya et al. 2004). In SARS-CoV the spike is able to retain specific binding affinity for the ACE2 of more than one host species, and rapid evolution to gain specificity for novel ACE2 species has been demonstrated ( $\mathrm{Li}$ et al. 2005b, 2006). The large size of the spike of coronaviruses may be related to the use of large host cell-surface molecules such as ACE2 as specific receptors. Amongst the coronavirus family, specific cellsurface receptors for the $S$ protein are all in the range of $60-110 \mathrm{kD}$ (Wentworth and Holmes 2001). These large host receptor molecules are of course functionally constrained and, in turn, relatively well conserved across species barriers. In utilizing binding to a large receptor molecule, the spike S1 domain also acts as a "spacer arm" holding the receptor far enough away from the threefold axis of symmetry of the spike S2 domain to permit fusion core rearrangement and subsequent membrane fusion. Such a property necessitates having a large spike molecule. Moreover, multiple receptor binding can have functional significance, enhancing the binding and entry of viruses. Cross-linking of adjacent host receptor molecules could increase the affinity of the virus for its target cell, as well as improving the kinetics of fusion. The SARS-CoV spike is a useful model system for the investigation of type 1 viral fusion protein dynamics. Utilizing this system for further research may lead to the possibility of developing broad-spectrum antivirals that target conserved cell fusion mechanisms shared by diverse virus families.

\section{References}

Baker KA, Dutch RE, Lamb RA, Jardetzky TS (1999) Structural basis for paramyxovirusmediated membrane fusion. Mol Cell 3:309-319

Beaudette FW, Hudson CB (1937) Cultivatiion of the virus of infectious bronchitis. J Am Vet Med Assoc 90:51-60

Beniac DR, Andonov A, Grudeski E, Booth TF (2006) Architecture of the SARS coronavirus prefusion spike. Nat Struct Mol Biol 13:751-752

Beniac DR, deVarennes SL, Andonov A, He R, Booth TF (2007) Conformational reorganization of the SARS Coronavirus spike following receptor binding: implications for membrane fusion. PLoS ONE 2(10):e1082. doi:10.1371/journal.pone.0001082 
Booth TF, Kournikakis B, Bastien N, Ho J, Kobasa D, Stadnyk L, Li Y, Spence M, Paton S, Henry B, Mederski B, White D, Low DE, McGeer A, Simor A, Vearncombe M, Downey J, Jamieson FB, Tang P, Plummer F (2005) Detection of airborne severe acute respiratory syndrome (SARS) coronavirus and environmental contamination in SARS outbreak units. J Infect Dis 191:1472-1477

Bullough PA, Hughson FM, Skehel JJ, Wiley DC (1994) Structure of influenza haemagglutinin at the $\mathrm{pH}$ of membrane fusion. Nature 371:37-43

Cheevers FS, Daniels JB (1949) A murine virus (JHM) causing disseminated encephalomyelitis with extensive destruction of myelin. J Exp Med 90:181-210

Chen L, Gorman JJ, McKimm-Breschkin J, Lawrence LJ, Tulloch PA, Smith BJ, Colman PM, Lawrence MC (2001) The structure of the fusion glycoprotein of Newcastle disease virus suggests a novel paradigm for the molecular mechanism of membrane fusion. Structure 9:255-266

Colman PM, Lawrence MC (2003) The structural biology of type I viral membrane fusion. Nat Rev Mol Cell Biol 4:309-319

Damico RL, Crane J, Bates P (1998) Receptor-triggered membrane association of a model retroviral glycoprotein. Proc Natl Acad Sci USA 95:2580-2585

Dimitrov DS (2004) Virus entry: molecular mechanisms and biomedical applications. Nat Rev Microbiol 2:109-122

Doyle LP, Hutchings LM (1946) A transmissible gastroenteritis in pigs. J Am Vet Med Assoc 108:257-259

Dutch RE, Jardetzky TS, Lamb RA (2000) Virus membrane fusion proteins: biological machines that undergo a metamorphosis. Biosci Rep 20:597-612

Earp LJ, Delos SE, Park HE, White JM (2005) The many mechanisms of viral membrane fusion proteins. Curr Top Microbiol Immunol 285:25-66

Fenouillet E, Barbouche R, Jones IM (2007) Cell entry by enveloped viruses: redox considerations for HIV and SARS-Coronavirus. Antioxid Redox Signal 9:1009-1034

Frank J, Radermacher M, Penczek P, Zhu J, Li Y, Ladjadj M, Leith A (1996) SPIDER and WEB: processing and visualization of images in 3D electron microscopy and related fields. J Struct Biol 116:190-199

Hakansson-McReynolds S, Jiang S, Rong L, Caffrey M (2006) Solution structure of the severe acute respiratory syndrome-coronavirus heptad repeat 2 domain in the prefusion state. J Biol Chem 281:11965-11971

Hernandez LD, Peters RJ, Delos SE, Young JA, Agard DA, White JM (1997) Activation of a retroviral membrane fusion protein: soluble receptor-induced liposome binding of the ALSV envelope glycoprotein. J Cell Biol 139:1455-1464

Hofmann H, Pohlmann S (2004) Cellular entry of the SARS coronavirus. Trends Microbiol 12:466-472

Kemble GW, Bodian DL, Rose J, Wilson IA, White JM (1992) Intermonomer disulfide bonds impair the fusion activity of influenza virus hemagglutinin. J Virol 66:4940-4950

Kobe B, Center RJ, Kemp BE, Poumbourios P (1999) Crystal structure of human T cell leukemia virus type 1 gp21 ectodomain crystallized as a maltose-binding protein chimera reveals structural evolution of retroviral transmembrane proteins. Proc Natl Acad Sci USA 96: $4319-4324$

Li W, Moore MJ, Vasilieva N, Sui J, Wong SK, Berne MA, Somasundaran M, Sullivan JL, Luzuriaga K, Greenough TC, Choe H, Farzan M (2003) Angiotensin-converting enzyme 2 is a functional receptor for the SARS coronavirus. Nature 426:450-454

Li F, Li W, Farzan M, Harrison SC (2005a) Structure of SARS coronavirus spike receptor-binding domain complexed with receptor. Science 309:1864-1868

Li W, Zhang C, Sui J, Kuhn JH, Moore MJ, Luo S, Wong SK, Huang IC, Xu K, Vasilieva N, Murakami A, He Y, Marasco WA, Guan Y, Choe H, Farzan M (2005b) Receptor and viral determinants of SARS-coronavirus adaptation to human ACE2. EMBO J 24:1634-1643

Li W, Wong SK, Li F, Kuhn JH, Huang IC, Choe H, Farzan M (2006) Animal origins of the severe acute respiratory syndrome coronavirus: insight from ACE2-S-protein interactions. J Virol 80:4211-4219 
Malashkevich VN, Schneider BJ, McNally ML, Milhollen MA, Pang JX, Kim PS (1999) Core structure of the envelope glycoprotein GP2 from Ebola virus at 1.9-A resolution. Proc Natl Acad Sci USA 96:2662-2667

Marra MA, Jones SJ, Astell CR, Holt RA, Brooks-Wilson A, Butterfield YS, Khattra J, Asano JK, Barber SA, Chan SY, Cloutier A, Coughlin SM, Freeman D, Girn N, Griffith OL, Leach SR, Mayo M, McDonald H, Montgomery SB, Pandoh PK, Petrescu AS, Robertson AG, Schein JE, Siddiqui A, Smailus DE, Stott JM, Yang GS, Plummer F, Andonov A, Artsob H, Bastien N, Bernard K, Booth TF, Bowness D, Czub M, Drebot M, Fernando L, Flick R, Garbutt M, Gray M, Grolla A, Jones S, Feldmann H, Meyers A, Kabani A, Li Y, Normand S, Stroher U, Tipples GA, Tyler S, Vogrig R, Ward D, Watson B, Brunham RC, Krajden M, Petric M, Skowronski DM, Upton C, Roper RL (2003) The Genome sequence of the SARS-associated coronavirus. Science 300:1399-1404

Moya A, Holmes EC, Gonzalez-Candelas F (2004) The population genetics and evolutionary epidemiology of RNA viruses. Nat Rev Microbiol 2:279-288

Penczek PA, Grassucci RA, Frank J (1994) The ribosome at improved resolution: new techniques for merging and orientation refinement in 3D cryo-electron microscopy of biological particles. Ultramicroscopy 53:251-270

Rota PA, Oberste MS, Monroe SS, Nix WA, Campagnoli R, Icenogle JP, Penaranda S, Bankamp B, Maher K, Chen MH, Tong S, Tamin A, Lowe L, Frace M, DeRisi JL, Chen Q, Wang D, Erdman DD, Peret TC, Burns C, Ksiazek TG, Rollin PE, Sanchez A, Liffick S, Holloway B, Limor J, McCaustland K, Olsen-Rasmussen M, Fouchier R, Gunther S, Osterhaus AD, Drosten C, Pallansch MA, Anderson LJ, Bellini WJ (2003) Characterization of a novel coronavirus associated with severe acute respiratory syndrome. Science 300:1394-1399

Sauter NK, Hanson JE, Glick GD, Brown JH, Crowther RL, Park SJ, Skehel JJ, Wiley DC (1992) Binding of influenza virus hemagglutinin to analogs of its cell-surface receptor, sialic acid: analysis by proton nuclear magnetic resonance spectroscopy and X-ray crystallography. Biochemistry 31:9609-9621

Simmons G, Gosalia DN, Rennekamp AJ, Reeves JD, Diamond SL, Bates P (2005) Inhibitors of cathepsin L prevent severe acute respiratory syndrome coronavirus entry. Proc Natl Acad Sci USA 102:11876-11881

Skehel JJ, Wiley DC (2000) Receptor binding and membrane fusion in virus entry: the influenza hemagglutinin. Annu Rev Biochem 69:531-569

Supekar VM, Bruckmann C, Ingallinella P, Bianchi E, Pessi A, Carfi A (2004) Structure of a proteolytically resistant core from the severe acute respiratory syndrome coronavirus $\mathrm{S} 2$ fusion protein. Proc Natl Acad Sci USA 101:17958-17963

Weissenhorn W, Dessen A, Harrison SC, Skehel JJ, Wiley DC (1997) Atomic structure of the ectodomain from HIV-1 gp41. Nature 387:426-430

Weissenhorn W, CarfiA LKH, Skehel JJ, Wiley DC (1998) Crystal structure of the Ebola virus membrane fusion subunit, GP2, from the envelope glycoprotein ectodomain. Mol Cell 2:605-616

Wentworth DE, Holmes KV (2001) Molecular determinants of species specificity in the coronavirus receptor aminopeptidase $\mathrm{N}$ (CD13): influence of N-linked glycosylation. J Virol 75: 9741-9752

Xu Y, Lou Z, Liu Y, Pang H, Tien P, Gao GF, Rao Z (2004) Crystal structure of severe acute respiratory syndrome coronavirus spike protein fusion core. J Biol Chem 279:49414-49419

Yin HS, Paterson RG, Wen X, Lamb RA, Jardetzky TS (2005) Structure of the uncleaved ectodomain of the paramyxovirus (hPIV3) fusion protein. Proc Natl Acad Sci USA 102: 9288-9293

Yin HS, Wen X, Paterson RG, Lamb RA, Jardetzky TS (2006) Structure of the parainfluenza virus $5 \mathrm{~F}$ protein in its metastable, prefusion conformation. Nature 439:38-44

Zhao X, Singh M, Malashkevich VN, Kim PS (2000) Structural characterization of the human respiratory syncytial virus fusion protein core. Proc Natl Acad Sci USA 97:14172-14177 